\title{
WHAT MAY I HOPE? WHY IT CAN BE RATIONAL TO RELY ON ONE'S HOPE
}

\section{SABINE DÖRING}

\author{
Universität Tübingen
}

\begin{abstract}
In hoping, what is important to us seems possible, which makes our life appear meaningful and motivates us to do everything within our reach to bring about the things that we hope for. I argue that it can be rational to rely on one's hope: hope can deceive us, but it can also represent things correctly to us. I start with Philip Pettit's view that hope is a cognitive resolve. I reject this view and suggest instead that hope is an emotion: hope is a felt evaluation for which we can define a corresponding character trait which in its turn qualifies as a virtue if it is felt whenever its correctness conditions are satisfied. For religious hope in particular it follows from my analysis that, if I believe, I may hope.
\end{abstract}

\section{INTRODUCTION}

Despite what might be suggested by the title, this talk is not about Kant and not even primarily about the philosophy of religion. In this paper, when I talk about hope, I do not mean a concept which is already religiously or politically charged. My concern is, first of all, with hopes that shape our everyday life, such as the hope that VFB Stuttgart defeated 1. FC Nürnberg on Thursday; or the hope that the faculty meeting tomorrow will be finished before my son's kindergarten closes; or the hope that the international community will get a handle on climate change; or simply the hope that the weather will be nice at the weekend. A characteristic of hope is that bringing about what one hopes for is to a certain extent, if not completely, beyond one's power. In this regard the secular hope that VFB Stuttgart defeated 1. FC Nürnberg on Thursday does not differ from religious hope. I will generally assume that the difference between 
religious and secular hope is simply a matter of their having different objects. Starting from this assumption, I believe that understanding what hope is and what role it plays in our life requires an analysis of a range of quite different hopes.

My focus will be on the question of whether it may sometimes be rational for us to rely on our hope. I shall answer this question in the affirmative and shall even claim that hope is a virtue of human beings as Rational Animals. I say 'even' because, traditionally, hope is suspected of being self-deceptive. A prime example is Friedrich Nietzsche who, referring to Hesiod's Pandora-myth, dismisses hope as 'the worst of all evils, because it protracts the torments of man' by blinding him to the fact of living in a world of hardship, disease, and suffering (Nietzsche 1996: fragm. 71). The aim of my talk is to refute a Nietzschean view: although hope does sometimes deceive us, it can also be appropriate and fulfils an indispensable function for our life.

Showing this demands, of course, an explanation of what hope is. Providing such an explanation is made difficult by the fact that hope, and secular hope in particular, has hitherto been largely ignored by philosophers. One of the rare exceptions is Philip Pettit. I will take his 2004 article Hope and Its Place in Mind as my starting point here, chiefly because Pettit deals therein with precisely the rationality of hoping (Pettit 2004). ${ }^{1}$

\section{HOPE AS A COGNITIVE RESOLVE}

Pettit begins with the attempt to find a core meaning in the term 'hope', the 'lowest common denominator that is present across the different usages possible' (p. 154). This analysis leads him to equate hope with a suitable a suitable belief-desire pair: the belief that a certain state of affairs may or may not obtain, where one desires that it does obtain (pp. 153-54). Hope thus appears to be an intentional mental state that involves two components: a cognitive belief and a conative desire.

The belief assigns a certain subjective probability to the desired state of affairs which must be neither 0 nor 1 . Hoping that something happens is inconsistent with believing for certain that it will not happen; it is equally inconsistent with believing for certain that it will. For example, it would be inconsistent for me to hope that I will spend my holidays at the Great

${ }^{1}$ Unless otherwise specified, all page references within this article refer to Pettit 2004. 
Barrier Reef when I know that I cannot afford the trip; for in that case I am aware that a trip to Australia is mere wishful thinking and therefore has a probability of occurrence of 0 . Conversely, Pettit's so-called 'core analysis' also excludes the possibility of hoping for something to happen to which I assign a probability of occurrence of 1 . When I have booked a trip to the Great Barrier Reef and am confident that I will make the trip, I do not feel hope but pleasant anticipation. And in order to be able to assert consistently 'I hope that VFB Stuttgart defeated 1. FC Nürnberg on Thursday', I must not yet know that they won 6:0.

To summarise: according to Pettit, hope consists basically of two components. First, a person who hopes that $p$ must assign a probability to $p$ which is greater than 0 and less than 1 . Secondly, the person must desire that $p$ obtains.

Now, Pettit dismisses this core analysis as too 'superficial' to capture hope in a 'substantial' sense. 'Substantial' hope, Pettit says, cannot be reduced to combinations of beliefs and desires but is a sui generis mental state which to have 'we might describe as cognitive resolve' (p. 159). This idea is modelled on Michael Bratman's influential 'belief-desire-intention model' (Bratman 1987). According to Bratman, the standard model of the explanation of action, the 'belief-desire model', is unable to account for the phenomenon of planning and for the intra- and interpersonal coordination of action which planning allows. As the name 'beliefdesire-intention model' already indicates, Bratman claims that this phenomenon can only be explained by bringing in intentions as a further class of mental states, in addition to beliefs and desires. Intentions are differentiated from desires via their functional role and rationality conditions, and yet they are, like desires, classified as pro-attitudes. By a 'pro-attitude' philosophers typically mean an attitude of wanting that the world be such that $\mathrm{p}$ is true, where $p$ stands for some yet to be realised state of affairs. Pro-attitudes thus provide ends for action, and this is why they are regarded as motivationally efficacious. As opposed to cognitive beliefs, which are said to represent the world as being such that their propositional content $p$ is true, pro-attitudes are defined as conative states (see Smith 1994). Pro-attitudes, some philosophers have argued, aim at changing the world in such a way that it fits them, whereas beliefs, conversely, aim at fitting the world. On Bratman's account, the crucial difference between ordinary pro-attitudes - desires - and intentions is that the latter are distinctive states of commitment to future action. Unlike a desire, Bratman says, an agent's intention, such as the 
intention to stick to a diet, constrains his future action by committing him to certain other intentions and actions, such as cutting out desserts or not buying sweets. According to Bratman, intentions thereby prevent us from being mere playthings of unpredictably coming and going desires. Instead, they enable us to control our actions, so as to coordinate those actions over time and with other agents. I am using first person plural pronouns here since Bratman considers the capacity for planning to be distinctive of human agents. In particular, planning is claimed to be 'pragmatically rational', which means that it optimises our utility (in the sense of satisfying our well-understood preferences). This claim is empirically supported by psychological studies showing that the capacity for impulse control (or deferred gratification) is a reliable indicator of social and professional success (Mischel et al. 1988).

So much for Bratman's model. This serves as Pettit's guide, but it is not something I want to criticize here. My concern is rather with Pettit's attempt to transfer this model to hope. Pettit introduces hope as a 'cognitive counterpart of planning' (p. 159). This is to say, hope commits its subject to certain beliefs, just as Bratman's intentions commit their agents to certain actions. Bratman therefore understands intention as practical resolve. Analogously, Pettit construes hope as cognitive resolve, namely as resolve to believe that the desired state of affairs is going to obtain or has at least a very good chance of obtaining (p. 158). Like planning, hoping is claimed to be pragmatically rational, that is, utilityoptimising. This is so by Pettit's lights because hope enables us to escape the danger of losing heart and throwing in the towel when we assign a relatively low probability to a desired state of affairs. Because of hope, so the story goes, even at this low level of confidence we nonetheless act as if the desired state of affairs is going to obtain, thereby making every effort within our power to bring it about rather than becoming demoralised and losing self-efficacy. In a nutshell, Pettit's 'substantial' hope consists in a 'cognitive strategy' of the following kind: the hoping person desires that a certain state of affairs $p$ obtains but assigns such a low probability of occurrence to $p$ that she is in danger of losing heart and her capacity to exercise agency effectively. Thanks to hope this danger is averted, as the person resolves upon taking the occurrence of $p$ as certain or at least as highly probable (almost certain). This cognitive resolve makes her psychically stable and enables her to engage actively in increasing $p$ 's probability of occurrence. 
What Pettit has in mind here is, for example, a cancer patient with bad prognosis. On Pettit's account, the patient's hoping saves him from becoming the victim of an ebb and flow of evidence for or against the possibility of his surviving, thereby enabling him to avoid the dangers of resorting to depression and self-pity. Instead, the patient decides to act as if it were certain or at least highly probable that he will survive, which according to Pettit means that the patient does everything within his reach to bring it about that he survives, thus actively improving his chance of survival. In another example, Pettit mentions those inmates of the Nazi concentration camps who managed to survive: 'substantial' hope, Pettit says, kept them from suicide or from just giving in (p. 159).

As can be seen from these examples, Pettit understands 'substantial' not just in the theoretical sense that hope cannot be reduced to an ordinary belief in combination with a desire or pro-attitude. Just as Bratman's intentions are conative pro-attitudes but no ordinary desires, Pettit's 'substantial' hope is a cognitive state, and yet no ordinary belief. 'Substantial' is obviously meant to refer throughout to 'deep' and 'pathetic' hopes, of which it is characteristic that the hoped-for thing is of vital importance to the subject. Secular hopes like my hope that the weather will be nice at the weekend, or that VFB Stuttgart defeated 1. FC Nürnberg on Thursday, are thus not captured by Pettit's analysis. Although I might well be seriously engaged in hoping for these things, normally, if I assign a low probability to their occurrence, there is no danger of me becoming demoralised and losing my capacity to exercise agency effectively.

Even if we grant that it is legitimate to conceive of substantial hope as a specific and specifiable kind of hope, it is easy to find examples which show that this kind of hope is not pragmatically rational. One counterexample is provided by Pettit himself, when he draws a parallel between substantial hope and precaution. Like hope, precaution is understood as a cognitive strategy. The difference between hope and precaution is that the precautious person does not desire that a certain state of affairs $p$ obtains, but fears that $p$ obtains, whilst again assigning a low probability of occurrence to $p$. According to Pettit, precaution then amounts to acting nonetheless as if $p$ is going to obtain, which is to make provisions for $p$ 's being the case, by which the person is supposed to decrease $p$ 's probability of occurrence and so to optimise her utility. Pettit's example is a client who fears that he will run into debts by renovating his house, as the renovation costs might be higher than 
budgeted for in advance by the craftsmen; although the client trusts the craftsmen's calculation, he resolves upon acting as if the renovation is becoming more expensive and thus decreases the possibility that he will run into debts.

Now, a person who fears that she will run into debts could equally be described as a person who desires that she will not run into debts. Let us, for the sake of argument, further assume that this person assigns a low probability to not running into debts - or that she assigns a high probability to running into debts. On Pettit's view, this person would have to hope substantially in order to preserve self-efficacy. However, she clearly would not optimise her utility, were she acting as if it were certain that she will not run into debts.

Such counterexamples are legion. They exemplify a maxim expressed by the proverb 'Hope for the best, but prepare for the worst', which also guides our reasonable handling of unlikely but disastrous events, such as an air crash or a nuclear MCA (maximum credible accident). Pettit breaks with this maxim: on his account, the hoping person thinks and acts on the conviction that the best certainly does come about, rather than preparing for the worst and protecting themselves against it. Yet on closer examination not even Pettit's own examples sustain this analysis. By undergoing treatments which possibly have harmful secondary effects and may even be themselves life-threatening, the seriously ill patient with a bad prognosis does not act as if the best will come about. In full accordance with the cited maxim, he rather seeks to avert the worst his death - by all the means available to him. Similarly, the inmates of the Nazi concentration camps fought for their survival: why should they have done so, had they taken it for granted that they would come through the Nazi horrors? It is therefore highly doubtful that it could ever be pragmatically rational (utility optimising) to adopt the cognitive strategy which Pettit identifies with substantial hope.

\section{HOPE AS A FELT EVALUATION}

Setting aside any reservations one may have about the precise details of Pettit's account, the key question is whether hope is a cognitive strategy in Pettit's sense. I don't share this view. From an epistemological point of view, it makes hope subject to Nietzsche's objection that hope is self-deception. Against this Pettit insists that substantial hope does 
not come down to self-deception but is 'make-believe' and as such 'at least evidentially not irrational': epistemic reasons are claimed to be outweighed by pragmatic ones in this case (p. 162). But we are not offered an argument for this claim and, in any case, we have just seen that it is not pragmatically rational to go for so-called 'substantial' hope.

Those in grip of the standard belief-desire model may be inclined to object that the correct cognitive strategy consists in taking the occurrence of what one hopes for, $p$, as possible rather than certain. This cognitive resolve seems to evade the counterexamples just mentioned and also seems compatible with the probability of occurrence assigned to $p$ - provided that this is neither 0 nor 1 , which possibility is excluded for conceptual reasons, according to Pettit. I present four arguments against this 'repair proposal':

(1) Hope cannot be understood purely strategically. Let us first consider the special case of religious hope: if a person hoped for purely strategic reasons, she would be like a person who came to believe in God because of Blaise Pascal's famous wager. Starting from the assumption that we are incapable of knowing whether God exists or not, Pascal (1910: sect. III) offers a decision-theoretical argument to the effect that we have reason to believe in God. Provided that the probability of God's existence is greater than zero, and provided further that going to heaven is infinitely much better than burning in hell, the expected utility of believing in God is higher than that of not believing in him. The expected gain of believing in God in the event that he exists outweighs the negligible costs of believing in God in the event that he does not exist; hence, believing in God is the dominant strategy. Even if we accepted this argument and thought it psychologically possible to make ourselves believe in God by virtue of a pragmatic decision, this belief would seem to be held for reasons which are of the wrong kind. Analogously, my reasons to hope for future redemption in God's kingdom would be of the wrong kind if I decided to hope for this simply because it would optimise my expected utility. The same applies to secular hope. Just imagine a bridegroom who hopes for the success of his marriage only in order to maximise his wellunderstood self interest. Whatever Nobel Prize winner Gary S. Becker might say here, in this case, the bridegroom's hope appears to us to rest on reasons of the wrong kind.

(2) Pascal's reasons are of the wrong kind because they are practical instead of epistemic reasons: they are reasons to bring it about that we believe in God, but not reasons to believe in God (see Skorupski 2007). 
In the same way, Pettit's reasons are reasons to bring it about that we hope, but not reasons to hope. Yet what could reasons to hope be?

(3) Reasons to hope stem from a value assigned to what one hopes for, which a purely strategic analysis of hope cannot but fail to capture. In hoping for future redemption in God's kingdom or for the success of his marriage, the subject ascribes a certain value to the object of his hope as such which cannot be reduced to the satisfaction of subjective preferences. The question of whether it is 'worthwhile' to hope is ambiguous: it does not merely ask whether it pays off for the subject to hope; it also asks whether what one hopes for merits that hope. Be it religious or secular hope, to hope for something is to see that thing as valuable in a way that goes beyond the standard of the theory of rational choice, and this is precisely why the examples just mentioned appear so absurd. Hope fits this diagnosis in that it conceptually implies an evaluation of its object as good in a certain sense. If someone claimed to hope that $p$ while at the same time denying that there is anything good about $p$, we would be conceptually excluded from understanding. As a consequence, we may assess hope, or rather the evaluation implied by it, for correctness or appropriateness, and reasons to hope (as opposed to reasons to bring it about that one hopes) are reasons in favour of this evaluation. (Let us be clear that Pettit cannot smuggle in this evaluation via the desire part of his model, since his desires are conative states and must not be transformed into their opposite, cognitive states.)

(4) Finally, a purely strategic analysis also misses the phenomenal aspect of hope, the 'what-it-is-like' to hope. Sometimes hope is joyful, sometimes it is anxious; in any case it is always inspired by a feeling of confidence of a certain degree. By contrast, both beliefs and desires lack phenomenality under the standard interpretation (Smith 1987).

Like many authors before me, I am here claiming that, first and foremost, hope is an emotion. As such, hope is no evaluative belief (or value judgement) but a felt evaluation for which we can define a corresponding character trait which in its turn can be associated with a virtue. In a way this leads us back to David Hume when he says: 'A propensity to hope and joy is real riches, one to fear and sorrow real poverty' (Hume 1964a: 220). 'In a way' because Hume does not seem to think of emotions as cognitive states, that is, as representational evaluations which are therefore subject to correctness conditions. Let us, for the sake of argument, nonetheless ascribe this currently predominant view of emotion to him, for then an analysis of hope along the lines of 
Hume's does show what a Pettit-style analysis attempts to but cannot show: that hope presents what is valuable as possible, thereby motivating us to make every effort within our power to bring it about.

Let us start with the relation between emotion and virtue. For any emotion we can define a corresponding character trait, namely the disposition to readily have that emotion. Jealousy is shown by jealous people, though people who do not have a jealous character can on occasion experience jealousy. Hope is shown by confident people, among others. And confidence is associated with the virtue of asserting itself at the right times, though this may not be traditionally considered a virtue. Character links to virtue links to emotion.

Primarily, hope is an emotion: a felt evaluation whose felt aspect necessarily involves feelings of confidence of a certain degree. Now, to feel confidence in hoping means seeing what one hopes for as being possible. Clearly, this kind of seeing something as possible essentially differs from the assignment of subjective probability. A similar view is to be found in Hume's Treatise. Like Pettit, Hume notes that hope need not bow to probability. Sometimes we continue to hope for something even when we believe, and know, that the occurrence probability of that thing is almost 0 . 'Hope dies last', so the proverb says. For an example, we need look no further than Pettit's cancer patient who holds on to his hope of survival, despite his gloomy prognosis. Alternatively, take the parents who, against all odds, never give up the hope that their abducted child will return safely, and who collapse only upon being confronted with their child's corpse. Pettit has it that, in such cases, the hoping person's desire that $p$ causes her to resolve upon making herself believe that $p$ is going to obtain, because of p's vital importance. Hume agrees that 'the smallness of probability is compensated by the greatness of the [good]' here (Hume 1964b: 220). But Hume's hoping person does not in any way decide to ignore actual probability for putatively good pragmatic reasons. Rather, this person's hope persists even though she believes, and even knows, that the occurrence of the 'good' is very unlikely. In other words, Hume allows for the possibility that a state of affairs $p$ may seem possible to us even if we assign a low probability of occurrence to $p$, provided that we value $p$ via hope as a particularly important good.

On Hume's account, this is possible precisely because, being an emotion, hope does not involve a belief about p's probability of occurrence. Provided that hope nonetheless has a representational content, that is, evaluates its object as good, it may instead be understood 
as a perception-like seeming (see Bealer 1998). As such, hope does not quantify this good as probable on a scale from 0 to 1 but presents it as possible, insofar as we feel confident that this good will be brought about. It speaks in favour of this view that there are many cases of hoping in which the subject would appear odd, if not neurotic, if he engaged in probability calculations: think again of the bridegroom who hopes for the success of his marriage...

Let us now turn to the question of how hope can make other states and actions rational. So far, hope has been introduced as an emotion which relates to a virtue. As an emotion, hope has been described as a felt evaluation which is not or does not involve a belief but resembles a perception. The analogy is instructive, since perceptual illusions like the famous Müller-Lyer illusion illustrate that perceptions may persist in spite of the subject's better judgment, without the subject being irrational. In perceiving the two Müller-Lyer lines, we cannot rid ourselves of seeing these lines as being of different lengths even when careful study has convinced us that they are the same length. But still, as long as the illusion is recognised as such and does not influence our thought and action, we are not irrational. In the same way, hope can rationally persist when we know that it deceives us. The cancer patient with a bad prognosis or the parents of the abducted child are not irrational simply because they hope. People are not irrational if they cannot help hoping even against better knowledge. They would be irrational only if they guided their thought and action as if it were certain that that the things for which they hoped would come about - which is precisely what Pettit claims.

However, when does hope deceive us, and when is it rational to rely on one's hope? I have argued that hope presents a not yet realised state of affairs as good and at the same time as possible, insofar as the subject feels confident to a certain degree that the state of affairs will be brought about. Accordingly, hope can deceive us in three different respects: (a) it can present as good what is in fact bad or evil; (b) it can present as possible what is actually impossible; (c) it can do both at once. In everyday language we say that, under these conditions, hope is inappropriate. The hope that my enemy will suffer a hard fate is inappropriate, and so is the hope that I will spend my holidays at the Great Barrier Reef when I obviously cannot afford the trip. However, depending on value and probability, hope can also be appropriate. In that case, it is rational for the subject to rely on their hope; in that case, we may hope in the sense that we are warranted in grounding our thought and action on our hope. 
Technically speaking, the appropriateness of hope is the correctness of its representational content. Similarly to a perception, hope represents the world as being a certain way: it represents a certain not yet realised states of affairs as a possible good. Therefore, hope is subject to correctness conditions which are meant to ensure that its representational content is correct: just as a perception of red is supposed to represent red things only, hope is supposed to represent as possible goods what really are possible goods. If a person relies on her hope - that is, takes her emotion's representational content at face value - she is rational to the extent that her emotion's correctness conditions are satisfied - or rather, to the extent that the correctness conditions of her emotion's representational content are satisfied. As a character trait corresponding to the emotion, hope qualifies as a virtue if it is felt whenever its correctness conditions are satisfied.

For the present, let me explain just one correctness condition to which we do submit hope in our everyday practice. We demand that, at least to a certain extent, the feeling of confidence involved in hope be consistent with actual probability. Although the possibility of what is hoped for envisaged in virtue of confidence is essentially different from probability, we dismiss hope as inappropriate when we assign to its object a probability of occurrence of 0 or near to 0 , depending also on the size of the value involved. Conversely, we have seen that if $p$ 's probability of occurrence equals 1 or is very high, we often regard pleasant anticipation rather than hope as the appropriate emotion. Although the felt possibility implied by hope must not be misinterpreted as cold-bloodedly calculated probability, we transform felt possibility into probability by determining threshold values above or below which we find hope inappropriate. This is to operationalise hope in terms of the aim of assessing its accordance with actual probability. The cancer patient's hope for recovery or the parents' hope for the safe return of their missing child may represent a good however great, but if the occurrence probability of the thing hoped for falls below a certain threshold value, we treat the hopes of these persons like the perception of the Müller-Lyer lines, as a mere illusion.

Once again, this is not to say that the cancer patient or the parents are irrational when they cannot give up their hopes in the face of actual probability. Like the perception of the two lines of the Müller-Lyer illusion, their hopes may be irrefutable, even though sadness, despair or resignation would be appropriate instead of hope. This does not itself 
make these persons irrational, for the rationality of a person depends on that she relies on her hope only if this emotion's correctness conditions are satisfied. As a character trait, hope is a virtue if it is readily felt under these conditions. Then we are justified in seeing the possibility of the future bringing good things, and this kind of seeing - 'affective perception' as I have called it elsewhere - is to a large extent independent of the probability assigned to those things.

The latter is crucial to hope as a virtue, and in particular to hope as a virtue of the Rational Animal. From what I have said so far it follows, first, that hope plays a crucial role in recognising valuable projects or chances and distinguishing them from projects or chances that are not valuable. One's unexpected state of hoping for something may for the first time lead one to judge that the thing is valuable. Secondly, hope allows for the possibility of hoping 'for the best' even in the face of low probability, and does so without forcing us to deceive ourselves or to engage in make-believe. To hope is to see the possibility of the future bringing good things, and this way of seeing is legitimate over a wide range of probability. Be it religious or secular, it is characteristic of hope that bringing its object about lies to a certain extent, if not completely, beyond our power. In hoping we are confident, which gives us stability in the ebb and flow of evidence for or against the likelihood of the occurrence of what we hope for. So what is important to us seems possible, which makes our life appear meaningful and motivates us to do everything within our reach to bring about the things about that we hope for. This is, I suppose, an evolutionary advantage of hoping, and it makes hope indispensable for long-term tasks or projects. By presenting the success of these tasks or projects as both valuable and possible, hope enables us to stay patient and to not become weak, as is exemplified by the hope of Abraham in The Epistle to the Romans (Rom.: 4-5). Nevertheless, hope must not make us blind to the true prospects of success.

It follows from the analysis suggested here that, for religious hope in particular, the rationality of hope requires that one at least does not rule out the occurrence of what one hopes for in order for this emotion to be rational. Religious hope necessarily requires faith, a faith, though, which has nothing to do with the calculation of probability and which in any case is significantly different from knowledge in the philosophical sense of true and justified belief: we cannot know that God exists; but conversely we cannot know that God does not exist. Therefore, the possibility of his existence and recurrence cannot rationally be excluded, and thus, 
if I believe in God, it is not irrational to hope. If I believe, I may hope. Finally, to quote Kant : 'Ich musste also das Wissen aufheben, um zum Glauben Platz zu bekommen' (KrV, B XXX) . In addition to this we may say: 'und um hoffen zu dürfen'.

\section{BIBLIOGRAPHY}

Bealer, George. 1998. 'Intuition and the Autonomy of Philosophy', in M. R. DePaul/W. Ramsey (ed.), Rethinking Intuition: The Psychology of Intuition and its Role in Philosophical Inquiry (Lanham, Md: Rowman \& Littlefield), pp. 201-204

Bratman, Michael. 1987. Intention, Plans, and Practical Reason (Cambridge, MA: Harvard University Press)

Hume, David. 1964a. 'The Sceptic', in Essays, Moral, Political, and Literary, Vol. 1, ed. by T. H. Green/T. H. Grose (Aalen: Scientia)

Hume, David, 1964b. A Treatise of Human Nature (in two volumes), Vol. 2, ed. by T. H. Green/T. H. Grose (Aalen: Scientia)

Kant, Immanuel. 1976. Kritik der reinen Vernunft, ed. by R. Schmidt (Hamburg: Felix Meiner)

Mischel, Walter/Shoda, Yuichi/Peake, Philip. 1988. 'The nature of adolescent competencies predicted by preschool delay of gratification', in Journal of Personality and Social Psychology, Vol. 54: 687-696

Nietzsche, Friedrich. 1996. Human, All Too Human: A Book For Free Spirits, transl. by R. J. Hollingdale, intro. by R. Schacht (Cambridge: Cambridge University Press)

Pascal, Blaise. 1910. Pensées, transl. by W. F. Trotter (London: Dent, 1910)

Pettit, Philip. 2004. 'Hope and Its Place in Mind', in Annals of the American Academy of Political and Social Science, Vol. 592: 152-165

Skorupski, John. 2007. 'Buckpassing about Goodness', in T. Rønnow-Rasmussen et al. (eds.), Hommage à Wlodek: Philosophical Papers Dedicated to Wlodek Rabinowicz. Available at: <http://www.fil.lu.se/hommageawlodek/index. htm $>$ [accessed 21/07/2014].

Smith, Michael. 1987. 'The Humean Theory of Motivation', in Mind, Vol. 96: 36-61

Smith, Michael. 1994. The Moral Problem (Oxford/Malden, MA: Blackwell) 